\title{
Knowledge and Practice Gap for Menstrual Hygiene among Adolescent School Girls of Tribal District of Maharashtra, India: A Cross Sectional Study
}

\author{
Meena Rakeri", Swati Bajirao Patil, Rakesh Waghmare \\ ${ }^{1}$ Professor, ${ }^{2}$ Junior Resident, ${ }^{3}$ Assistant Professor, Department of Community Medicine, Grant Government Medical \\ College, Mumbai 40008, Maharashtra, India. \\ DOI: https://doi.org/10.24321/2349.2880.201816
}

AbstraCt
Introduction: Hygiene-related practices of adolescents during menstruation are of importance, as poor
hygiene might increase vulnerability to reproductive tract infections (RTI). Therefore, increased knowledge
about menstruation right from childhood may escalate safe practices and may help in mitigating the
suffering of women.
Aims and Objectives: (1) To assess the knowledge and practices about menstrual hygiene among school
going adolescent girls. (2) To evaluate health seeking behaviour among the study subjects.
Methodology: This was a cross sectional study done in three randomly selected Government High Schools in
tribal District Palghar from Jan-Feb 2018. A pre-designed, pre-tested and structured questionnaire was used.
Data were compiled in an Excel sheet and were analysed by using EPI info statistical software (version2.3.1).
Results: A total of 277 girls were interviewed, the mean age was 14 years. Majority of girls were aware
about menstruation prior to the attainment of menarche. Mothers were first informant in about $69.6 \%$
girls. But correct reason and source of bleeding was not known to most of respondents. Overall $63.8 \%$
adolescent girls were using sanitary napkins as menstrual absorbent while 36.1\%were using old used cloth
and 13.7\%were using both.
Conclusion: There is need to educate the girls about menstruation, its importance and hygiene maintenance
so as to enable them to have healthy and productive life in future.
Keywords: Girls, Menarche age, Menstrual absorbents, Menstrual hygiene, Practices

\section{Introduction}

The World Health Organization (WHO) has defined adolescence as the age group of 10-19 years. There are an estimated 238 million adolescents in India who comprise $19 \%$ of the total Indian population. ${ }^{1}$ Menstruation is a phenomenon unique to the females. The onset of menstruation is one of the most important changes occurring among the girls during the adolescent year. Adolescent girls constitute a vulnerable group, particularly

Corresponding Author: Dr. Swati Bajirao Patil, Department of Community Medicine, Grant Government Medical College, Mumbai 40008, Maharashtra, India.

E-mail Id: swati.shinde2009@rediffmail.com

Orcid Id: https://orcid.org/0000-0003-3227-5079

How to cite this article: Kakeri M, Patil SB, Waghmare R. Knowledge and Practice Gap for Menstrual Hygiene among Adolescent School Girls of Tribal District of Maharashtra, India: A Cross Sectional Study. Ind J Youth Adol Health 2018; 5(3): 23-27. 
in India where female child is discriminated in the society and people in India are still living in a conservative society. Menstruation is still regarded as something unclean or dirty in India, although menstruation is normal process, it is linked with several misconception and practices which sometimes result into adverse health outcome. ${ }^{2}$ Poor personal hygiene and unsafe sanitary conditions have also primarily resulted in gynecological problems among the adolescent girls. It was also reported that repeated use of unclean napkins or the improperly dried cloth napkins before its reuse results in harboring of micro-organisms and causing vaginal infections. ${ }^{3}$

Many studies have revealed that most of the adolescent girls had incomplete and inaccurate information about the menstrual physiology and hygiene. Good hygienic practices such as the use of sanitary pads and adequate washing of the genital area are essential during menstruation. Women and girls of the reproductive age need access to clean and soft, absorbent sanitary products which can in the long run, protect their health. ${ }^{4}$

Palghar is the $36^{\text {th }}$ district of Maharashtra created by bifurcating the Thane district on 1st August 2014. It is small tribal district with variable geographic terrains from plain area to coastal areas. Very few studies from this district have been published on the knowledge, practices of adolescent girls regarding menstruation hygiene and menstrual problems. This study attempts to throw some light on the magnitude of the problem in the area, so that interventions can be planned in near future.

\section{Objectives}

The objectives of the study are:

- To assess the knowledge about menstrual hygiene among school going adolescent girls.

- To evaluate practices regarding menstrual hygiene and health seeking behaviour among the study subjects.

\section{Materials and Methods}

This was a cross sectional study done from Jan-Feb 2018 in three out of ten randomly selected High Schools in rural area of the Palghar District. After taking permission from the school authority, the class teachers of the respective classes were explained the objectives of the study. The study population included all the girls studying in $8^{\text {th }}, 9^{\text {th }}$ and $10^{\text {th }}$ standards. The study includes only those girl students of these three standards who have attended their menarche. 277 girl students of $8^{\text {th }}, 9^{\text {th }}$ and 10 th standards were enrolled in the present study.

The study carries out on only two days of week i.e. Wednesday and Friday of January and February of 2018 in afternoon from 2 to 4 PM to avoid disturbance of their routine classes. Initial micro planning was done to execute the study and on each day of data collection, only one section of each standard which compromises on an average 25 girls were select The students were explained the purpose of the study and were briefed about the questionnaire in their local language. After obtaining an informed consent, the questionnaires were administered to them. The study tool used was a pre-designed, pretested, structured and self-administered questionnaire which was developed and translated into local language. The questionnaire included Socio- demographic profile, Perceptions included Knowledge and Attitudes regarding the process of menstruation, menstrual history, Practices during menstrual cycles and menstruation related problems.

Specific time duration was given to answer all the questions. This was followed by a talk on the normal physiology of menstruation, the importance of maintaining hygiene and safe hygienic practices during menstruation. Queries and concerns of the participants were also addressed. Data were then compiled in an Excel sheet and were analysed by using Epi info statistical software ( version 2.3.1).

\section{Inclusion criteria}

Girls who were studying in class 8,9 and 10th standard and who had attain menarche and give consent.

\section{Exclusion Criteria}

Girls who are absent during data collection.

\section{Results}

\section{Knowledge Regarding Menstruation}

A total 277 girls were enrolled in present study studying in $8^{\text {th }}, 9^{\text {th }}$ and $10^{\text {th }}$ standard. The mean age of the respondent is 14 years. $79.06 \%$ of the girls correctly described the age of menarche i.e. 12-16 years of age. Participants recommend that modal duration of flow and modal duration of Cycle is 4.6 days and 28.78 day respectively. $54.1 \%$ of girl consider age is the causative factor for beginning of menstrual cycle and only $34.4 \%$ girls told about Uterus being the organ involved in it. 
Table 1.Knowledge and practices among study population

\begin{tabular}{|c|c|c|}
\hline Parameters & $\begin{array}{c}\text { Frequency } \\
(n=277)\end{array}$ & Percentage \\
\hline \multicolumn{3}{|c|}{ A. Age at menarche (in years) } \\
\hline$<12$ & 30 & $10.83 \%$ \\
\hline 12 to 16 & 219 & $79.06 \%$ \\
\hline$>16$ & 28 & $10.1 \%$ \\
\hline \multicolumn{3}{|c|}{ B. Cause for menstruation } \\
\hline Age & 150 & $54.15 \%$ \\
\hline Hormones & 105 & $37.9 \%$ \\
\hline Curse & 7 & $2.5 \%$ \\
\hline Enzymes & 15 & $5.1 \%$ \\
\hline \multicolumn{3}{|c|}{ C. Organ } \\
\hline Bladder & 27 & $9.74 \%$ \\
\hline Uterus & 95 & $34.4 \%$ \\
\hline Fallopian tube & 44 & $15.8 \%$ \\
\hline Vagina & 111 & $40,1 \%$ \\
\hline \multicolumn{3}{|c|}{ D. Informer } \\
\hline Mother & 185 & $69.67 \%$ \\
\hline Friend & 43 & $15.8 \%$ \\
\hline Relative & 6 & $2.8 \%$ \\
\hline Teacher & 28 & $11.5 \%$ \\
\hline Other & 15 & $2.5 \%$ \\
\hline
\end{tabular}

Social stigma is still associated with menstrual cycle, 214 (77\%) are not allowed to attend any religious occasion. Food taboos were common during menstruation, 19\% avoided certain food items. Mother was the first informant in, 185 $(69.6 \%)$ subjects and friends in 43 (14.8\%). Other sources of information were teachers and closed relatives etc.

Table 2.Practices

\begin{tabular}{|c|c|c|}
\hline \multicolumn{3}{|c|}{ A. Age at menarche } \\
\hline 10 to 11 & 16 & $5.7 \%$ \\
\hline 12 to 14 & 243 & $87.7 \%$ \\
\hline 15 to 16 & 18 & $6.4 \%$ \\
\hline \multicolumn{3}{|c|}{ B. Absorbent use } \\
\hline Pad & 177 & $63.80 \%$ \\
\hline Cloth & 100 & $49.80 \%$ \\
\hline Both & 38 & $13.70 \%$ \\
\hline C. Frequency of change of absorbent \\
\hline 2 pads/day & 66 & $23.80 \%$ \\
\hline 3 pads/day & 153 & $55.20 \%$ \\
\hline 4 pads/day & 58 & $20.90 \%$ \\
\hline \multicolumn{2}{|c|}{ D. Cleaning practices - cloth user } \\
\hline Water & 2 & $1.4 \%$ \\
\hline Soap \& water & 112 & $81.15 \%$ \\
\hline Antiseptic solution & 24 & $17.4 \%$ \\
\hline \multicolumn{2}{|c|}{ E. Area of drying for cloth user } \\
\hline Sunshine & 62 & $44.9 \%$ \\
\hline Bathroom & 45 & $32.6 \%$ \\
\hline Hidden place & 31 & $22.4 \%$ \\
\hline \multicolumn{2}{|c|}{ F. Reasons for not using pads } \\
\hline
\end{tabular}

\begin{tabular}{|c|c|c|}
\hline Cost & 82 & $59.40 \%$ \\
\hline Lack of knowledge & 12 & $8.60 \%$ \\
\hline Nonavaibility & 44 & $31.80 \%$ \\
\hline \multicolumn{3}{|c|}{ G. Menstrual irregularity } \\
\hline Delayed & 65 & $23.4 \%$ \\
\hline Polymenorrhoea & 41 & $14.8 \%$ \\
\hline Dysmenorrhea & 44 & $15.8 \%$ \\
\hline Menorrhagia & 32 & $11.5 \%$ \\
\hline No complains & 95 & $34.2 \%$ \\
\hline \multicolumn{3}{|c|}{ H. Menstrual problems } \\
\hline White discharge & 93 & $33.5 \%$ \\
\hline Itching & 26 & $9.3 \%$ \\
\hline Burning micturition & 13 & $4.6 \%$ \\
\hline No complains & 145 & $52.3 \%$ \\
\hline
\end{tabular}

\section{Practices during Menstruation}

Out of the total 277 students studied, the modal age of attainment of menarche is 13 years. 138 (63.8\%) girls were using sanitary pads during menstruation, 100 (36.1\%) girls old used cloth and 38 (13.7\%) both cloth and pads. Among the study population who used cloth as absorbent large proportion of girls used soap and water to clean them. $17.1 \%$ used antiseptic solution along with water, only 62 $(44.8 \%)$ girls dried these washed clothes in the sun, $32.6 \%$ in the bathroom and $22.4 \%$ dried in hidden places. The query on the frequency of change of cloth or pad during the time of menstruation revealed that, 153 (55.2\%) changed three times a day, 66 (23.8\%) twice a day and 58 (20.9\%) four times a day. The main reasons for not using sanitary napkins during menstruation is the cost as mentioned by 82 (59.4\%) study subjects, 44 (31.8\%) mentioned about non-availability of napkins in nearby area and 12 (8.6\%) has lack of knowledge about the napkins.

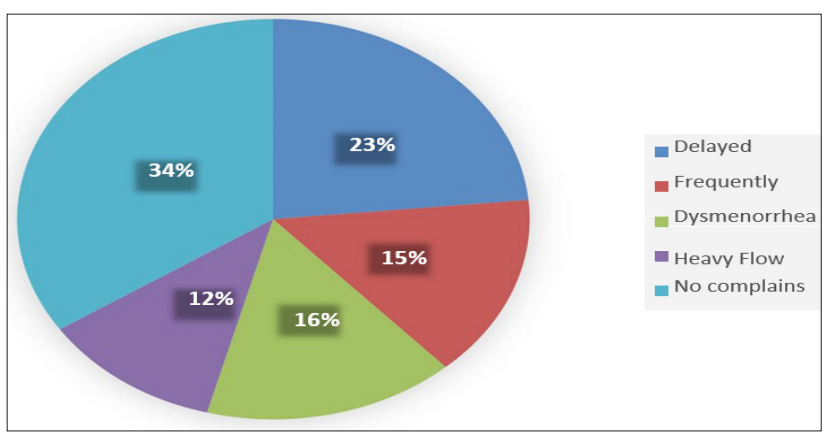

Figure 1.Menstrual irregularity in study population

\section{Health Seeking Behaviour}

Out of 277 study population, 183 (66.01\%) girls had experienced menstrual irregularity and dysmenorrhoea. As seen in figure-1, 65(23.4\%) had delayed menses, $41(14.8 \%)$ had polymenorrhoea, 44(15.8\%) had dysmenorrhoea and $32(11.5 \%)$ had menorrhagia. Queries regarding complains associated with menstrual problems 132 (52.3\%) had 
complains. Large number of girls 93 (33.5\%) in study population complains about white discharge, 27 (9.3\%) about itching at genital area and 13 (4.6\%) complains about burning micturition. When these girls were asked about, from whom they took advice or treatment for the same complains, 78 (59.1\%) took advice from mother, 9 (6.8\%) from private doctors and 6 (4.5\%) from government hospitals while 38 (28.7\%) did not seek any advice.

\section{Discussion}

Menstrual hygiene is taboo, a topic that most women in India are uncomfortable discussing in public. This is compounded by gender inequality which excludes women and girls from decision making process. ${ }^{5}$ Hygiene related practices of women during menstruation are of considerable importance as it affects health by increasing vulnerability to infection especially the infections of urinary tract and perineum. ${ }^{2}$ This study was planned to know the knowledge and practices of adolescent girls in tribal district of Maharashtra, so that results can further be used for some intervention according to needs.

This study revealed that the modal age of the menarche in girls was 13 years. Another researcher reported that the age of the menstruating girls ranged from 12-17 years, with the maximum number of girls being between 13-15 years of age. ${ }^{6}$ In our study population, only $34.4 \%$ girls were having correct knowledge about the source of bleeding during menstruation, similarly in study of South India one third of girls identified uterus as source of bleeding while as many as $28 \%$ girls identified the urinary bladder as its source. ${ }^{7}$

Most of the girls were aware of menstruation before menarche. It was observed that the most common source of information were mothers which retells the fact that mothers of adolescent girls should be essential part of all programs on adolescent health and especially menstrual hygiene so that hygienic menstrual practice will go a long way in maintaining a healthy reproductive tract for each and every girl child, who after she becomes a mother, will disseminate this healthy message to her offspring. It was seen that though almost all girls had heard about menstruation, the level of knowledge was poor which is similar to study by Shanbhag D et al. ${ }^{8}$ Other sources of information were friends, teachers and close relatives for the study girls.

Different restrictions were practiced by most of the girls in the present study, possibly due to the different rituals in their communities; the same were practiced by their mothers or other elderly females in the family, due to their ignorance and false perceptions about menstruation. These findings were consistent with those of other studies. 2, 4, 9

Even if the sanitary pad is hygienic and safe option as an absorbent, it was seen in the present study that two out of five girls were using old reused cloth as absorbent. A similar study which was undertaken among adolescent school going girls in Saoner, in the Nagpur district reported the use of old clothes in $45.74 \%$ of the subjects. ${ }^{6}$ Our study group reported that majority of girls who used old cloth, washed the cloth with soap water and dried them in bathroom or any hidden place such practices may be harmful and leads to reproductive tract infection. Other researchers, in their studies, also reported that more than three fourth of the girls used cotton clothes and reused them after washing them. ${ }^{4,10,11}$

Very few girls from the tribal areas used sanitary pads which were available in the market; due to cost of napkins, lesser availability of the pads and lack of awareness.

Present study showed $11.5 \%$ girls suffered from dysmenorrhea Comparatively high prevalence had been reported by Sharma A, Taneja DK, Sharma P, et al. (33\%), Nag (33.84\%). ${ }^{12,13}$

\section{Conclusion}

This study reveals that menstrual hygiene is not very satisfactory among a large proportion of the adolescent girls. It also shows that majority of the girls trusted on mothers for advice on reproductive health problems or nutrition or any other health problems.

\section{Recomandations}

Health professionals should organize educative sessions for parents especially mothers (as they were trusted as adviser by most adolescent girls) so that they can be trained to give adequate knowledge on reproductive health problems to their children.

\section{Acknowledgements}

We thank Dr. Shriram Gosavi, Incharge and the staff of Rural Health Training Centre, J.J. Hospital, Palghar, and staff and students of the high schools, for making this study possible.

\section{Conflict of Interest: None}

\section{References}

1. UNICEF. The State of the World's Children 2014 in numbers: revealing disparities, advancing children's rights. UNICEF, New York. 2014.

2. Dasgupta A, Sarkar M. Menstrual hygiene: How hygienic is the adolescent girl? Indian Journal of Community Medicine 2008; 33(2): 77.

3. Paul D. A Report of an ICMR funded research project: knowledge and practices of adolescent girls regarding reproductive health with special emphasis on hygiene during menstruation. National Institute of Public Cooperation and Child Development (NIPCCD), New 
Delhi. 2007.

4. Mudey AB, Keshwal N, Mundey GA et al. A cross sectional study on awareness regarding safe and hygienic practices amongst school going adolescent girls in a rural area of Wardha district. Global Journal of Health Science 2010; 2(2): 225-31.

5. Juyal R, Kandpal SD, Semwal J et al. Practices of menstrual hygiene among adolescent girls in a district of Uttarakhand. Indian Journal of Community Health 2012; 24(2): 124-8.

6. Thakre SB, Thakre SS, Reddy M et al. Menstrual hygiene: knowledge and practice among adolescent school girls of Saoner, Nagpur district. Journal of Clinical and Diagnostic Research 2011; 5(5): 1027-33.

7. Is menstrual hygiene and management an issue for adolescent girls. Water Aid in South Asia, 2009. Available from: http://menstrualhygieneday.org/ wp-content/uploads/2016/12/Wateraid_menstrualhygiene-school-adolesencegirls-Nepal_2009.pdf.

8. Shanbhag D, Shilpa R, D'Souza N et al. Perceptions regarding menstruation and practices during menstrual cycles among high school going adolescent girls in resource limited settings around Bangalore city, Karnataka, India. International Journal of Collaborative
Research on Internal Medicine \& Public Health 2012; 4(7): 1353.

9. Narayan KA, Shrivastava DK, Pelto PJ et al. Puberty rituals, reproductive and health of adolescent school girls of south India. Asia Pacific Population Journal 2001; 16: 225-38.

10. Khanna A, Goyal RS, Bhavsar R. Menstrual practices and reproductive problems: A study of adolescent girls in Rajasthan. Journal of Health Management 2005; 7(1): 91-7.

11. Quazi SZ, Gaidhane A, Singh D. Beliefs and practices regarding menstruation among the adolescent girls of high schools and junior colleges of the rural areas of Thane district. Journal of DMIMSU 2006; 2: 76.

12. Sharma A, Taneja DK, Sharma P, et al. Problems related to menstruation and their effect on daily routine of students of a medical college in Delhi, India. Asia Pac J Public Health 2008; 20(3): 234-41.

13. Nag RM. Adolescent in India. Medical Allied Agency, Calcutta. 1982: 18-26.

Date of Submission: 2018-08-14 Date of Acceptance: 2018-08-22 